\title{
LXXVI. Multiple atomic disintegration. A suggestion in radioactive theory
}

\section{Frederick Soddy M.A.}

To cite this article: Frederick Soddy M.A. (1909) LXXVI. Multiple atomic disintegration. A suggestion in radioactive theory , Philosophical Magazine Series 6, 18:107, 739-744, DOI: $10.1080 / 14786441108636745$

To link to this article: http://dx.doi.org/10.1080/14786441108636745

曲 Published online: 21 Apr 2009.

Submit your article to this journal $\sqsubset \pi$

Џll Article views: 4

Q View related articles $\square$

Citing articles: 4 View citing articles $\square$ 
the separate factors, and thus can be forced into synchronous motion. This oscillation-region involves also the so-called free oscillation-period ; if we determine $\omega_{x}$ correspondingly, resonance will arise between the rotation and the oscillation, and thereby result the strongest tendency to oscillate. This shows us the manner, in which, even when large gyrostatic moments exist, short periods of oscillation may be obtained, namely, by compensating the inertia by simple stiffening of the control-spring $\left(F_{r}\right)$, because in the case of resonance the greatest possible amplitude of oscillation is the resultant of the directing and deflecting forces' combined action; the ratio $\omega_{x} / \omega_{n}$ is here to be taken accordingly large. By means of suitable transformations (electromagnetic synchronous motors or the like) the ratio $\omega_{\gamma}^{*} / \omega_{x}$ may then be forced to an equally constant magnitude as that of the oncefor-all determined magnitudes of mass and moment of inertia of the regarding parts of the constructed instrument.

For practical needs we might employ two or more gyrostats of smaller construction, oscillating in one frame together round a common axis $y$, rather than a single larger gyrostat, so as to combine two or more such systems with axes $y$, shifted round through equivalent angles with respect to one another, their bearings either over one another in a single framework, rotating about the vertical $x$, or again each in a forked bearing rotating individually, the synchronous motions of all the bearings maintained with a constant phase-difference between them in the same manner as in the control of electrical clocks, equally at distant points of the ship, whereever these synchronously-acting instruments may be installed, - whilst their paths of connexion count amongst the numerous nervous fibres of that gigantic creature, the modern oceanrunner.

Hohenwaldau, near Stuttgrit. February 13,3908 .

LXXVI. Multiple Atomic Disintegration. A Suggestion in Radioactive Theory. By Frederick Sondy, M.A.*

THE cause of atomic disintegration remains unknown. It is difficult to construct any model of the disintegrating mechanism, chiefly on account of certain features in connexion with the process. In particular may be mentioned the fact that the period of average lite of the atoms disintegrating is the same whether newly formed atoms or those which have

* Communicated by the Author. 
already survived many times the average period are considered. What may be termed the inevitableness of the process, and its entire independence of all known conditions, suggests that the cause of disintegration is apart from the atom. It is difficult to believe that the cause is resident in space external to the atom. It seems more probable that it exists within the atom and at the same time is uninfluenced by it. The question about to be discussed is whether necessarily only one mode of instability can exist witbin the atom at the same time.

In certain problems in radioactivity it is becoming necessary to take into account that the same element, for example uranium, may give rise to two different series of disintegration products, represented for example by actinium and radium. Rutherford has suggested in order to account for the small quantity of actinium, relatively to radium, in minerals that actinium may be formed from uranium as a side or branch chain, not in the main line of descent. The suggestion in this paper is that multiple modes of disintegration may be proceeding simultaneously and independently within the same atom. There is nothing in this idea opposed to all that is known of the character of atomic disintegration. On the other hand it will be shown that such disintegrations would simulate closely in many respects simple disintegration.

It has been established that the law of simple disintegration really expresses the operation of the law of probability for a process selecting the particular individual atoms disintegrating without reference to the character of the individuals, but solely according to the total number in existence. That is to say, the period of actual life of the individual remains indefinite up to the moment of disintegration, and no process of sorting a collection of atoms into long-lived and short-lived varieties is even conceivable. Similarly for multiple disintegration the view advocated is that the law of simple disintegation applies to each mode of disintegration exactly as if it were the only one in operation. It follows that the question by which particular mode any individual atom will disintegrate remains indefinite up to the moment of disintegration and no process is conceivable which would sort a collection of atoms according to the mode by which eventually they will disintegrate and to the product which eventually they will produce.

If for the same atom two modes of disintegration can occur independently, the constant of the first mode being represented by $\lambda_{A}$ and that of the second by $\lambda_{x}$, the quantity 
$\mathrm{Q}$ of the substance will diminish according to the differential equation

$$
\begin{aligned}
\frac{d \mathrm{Q}}{d t} & =-\lambda_{\mathrm{A}} \mathrm{Q}-\lambda_{\mathrm{X}} \mathrm{Q} \\
\text { or } \quad \frac{\mathrm{Q}_{t}}{\mathrm{Q}_{0}} & =\epsilon^{-\left(\lambda_{\mathrm{A}}+\lambda_{\mathrm{x}}\right) t},
\end{aligned}
$$

where $Q_{t}$ is the quantity remaining at time $t$ and $Q_{0}$ the initial quantity.

That is to say, for a radio-element undergoing a dual disintegration the quantity would diminish exponentially with the time as in a simple disintegration. The radioactive constant of the multiple change would be the sum of the separate constants. If, for example, $\alpha$-rays were given out in one of the modes of disintegration, and $\beta$-rays in the other, each type of radiation would decay at the same period, namely, the sum of the two separate periods. The same holds true whatever the number of modes of disintegration. So that multiple disintegration would not be easy to detect so far as ordinary criteria go. But with regard to the products formed in the various modes there will be constancy of proportionality between them. To suggest a concrete case, let us suppose the disintegration of uranium $\mathrm{X}$ is dual, one mode producing ultimately radium, the other ultimately actinium, and let the constant $\lambda_{\mathrm{A}}$ apply to the radium mode and $\lambda_{\mathrm{x}}$ to the actinium mode of disintegration. Then the ratio between the number of uranium atoms forming radium and the number forming actinium is given by $\frac{\lambda_{\Delta}}{\lambda_{x}}$. If the further disintegrations of both these elements are simple the same ratio will express the relation between the quantities of the final inactive products of the two series. This suggests at once a method of obtaining evidence of the process and at the same time of determining the nature of the final products. If a constant ratio were found between any two inactive elements present in uranium minerals it would be very strong evidence from the present point of view.

According to the researches of Boltwood (Am. Journ. Sci. 1908, p. 296) on the proportionate $\alpha$-radiation contributed by the separate constituents in equilibrium in uranium minerals, it is possible to deduce (Phil. Mag. Oct. 1908, p. 517) that of eight atoms of uranium seven go to form radium and one to form actinium. The ratio $\frac{\lambda_{A}}{\lambda_{x}}$ is therefore equal to 7 . 
This is also the ratio between the quantities of the endproducts of the two series in minerals on the assumption stated.

Proceeding with the idea that the disintegration of uranium $\mathrm{X}$ is dual, it makes no difference whether we regard the $\beta$ - and $\gamma$-rays as derived from one only or from both of the modes of disintegration. Or, we may even suppose that the $\beta$-rays come from the radium mode, while $\gamma$-rays come from the actinium mode of disintegration, which appears to have something to recommend it as it would explain the relative poverty of uranium in $\gamma$-rays (Soddy and Russell, Phil. Mag. Oct. 1909, p. 631). Both types of rays would decay at the same rate. The apparent value of the radioactive constant of uranium $\mathrm{X}$ (about $\cdot 031$ (day) $^{-1}$ ) would be the sum of the two separate constants, one of which is seven times the other. The radium mode would thus have the constant $\cdot 027$ and the actinium mode of disintegration, $\cdot 004$.

This point of view explains perfectly the known relations between uranium, actinium, and radium, preserving the inevitableness of the phenomenon, without the necessity of supposing, as on Rutherford's theory of a side-chain, that actinium is not a lineal descendant of uranium in the same sense as radium is ('Radioactive 'Transformations,' p. 177). Considering the long series of successive disintegrations passed through by the radioactive atoms it would be rather remarkable from one point of view if multiple disintegration did not sometimes occur. The relations between thorium and uranium in minerals would receive perhaps a better explanation on the view that thorium is one product of a multiple disintegration in the uranium series. The evidence has been discussed by Boltwood (Am. Jour. Sci., J905, xx. p. 256) who concluded that it was most probable that thorium was a disintegration product of uranium. The period of thorium is probably five times as long as that of uranium, and hence thorinm cannot be intermediate between uranium and radium as in this case there should be a constant ratio between thorium and radium in equilibrium and not between uranium and radium. On the present idea the ratio of thorium to uranium and to the end-products of radium can be calculated but the expressions involve the age of the mineral. These expressions are

$$
\begin{gathered}
\frac{\mathrm{T}}{\mathrm{U}}=\frac{\lambda_{\mathrm{A}}}{\lambda_{\mathrm{B}}-\lambda_{\mathrm{A}}-\lambda_{\mathrm{X}}}\left(1-\epsilon^{\left(\lambda_{\mathrm{A}}+\lambda_{\mathrm{X}}-\lambda_{\mathrm{A}}\right) t}\right) \\
\mathrm{T}=\frac{\lambda_{\mathrm{A}}\left(\lambda_{\mathrm{A}}+\lambda_{\mathrm{X}}\right)}{\mathrm{E}}=\left(\frac{\epsilon^{-\lambda_{\mathrm{B}} t}-\epsilon^{-\left(\lambda_{\mathrm{A}}+\lambda_{\mathrm{X}}\right) t}}{1-\epsilon^{-\left(\lambda_{\mathrm{A}}+\lambda_{\mathrm{X}}\right) t}}\right)
\end{gathered}
$$

where $t$ is the age of a mineral, assumed to contain no thorium 
or end-product initially; $\mathrm{T}, \mathrm{U}$, and $\mathrm{E}$, the existing quantities of thorium, uranium, and end-product of radium ; $\lambda_{\Delta}, \lambda_{x}$ the constants of the thorium and radium modes in the multiple disintegration of uranium; $\lambda_{B}$ the constant of thorium itself, and $k$ is the fraction of the number of uranium atoms undergoing the radium mode of disintegration which eventually become atoms of the end-product in question. Were all subsequent disintegrations simple $k$ of course would be unity. The effect of the intermediate bodies between uranium and the endproduct has been neglected. So far as is known this would be small. Unfortunately on account of the long period of thorium and the isomorphism of uranium and thorium oxides it is doubtful if much evidence can be derived from the composition of minerals. Thorianite is regarded as an extremely old mineral geologically yet it contains so great a percentage of thorium that from the point of view of radioactivity it must be a recent formation. As Boltwood has pointed out (loc. cit. p. 262), Hillebrand's analyses of uranium minerals show generally that the percentage of total rare earths (less perfectly of the thorium) increases as the lead increases but there are numerous exceptions. It is probable that geological time is all too short to enable the necessary evidence to be obtained from the composition of minerals.

Before concluding a special case may be referred to which has some points of interest and might very probably occur. If one of the modes of disintegration were a relatively mild form of rearrangement, rather than an explosive disintegration, it is conceivable that the ray-producing change might occur with the same period independently of whether the rayless change had or had not occurred, expelling the same character of ray in each case. On this view actinium would proceed from rearranged but undisintegrated uranium $X$, radium from uranium $\mathrm{X}$ disintegrating directly, or vice versa. If $\lambda_{\mathbf{\Delta}}$ represents the constant of the rayless and $\lambda_{x}$ that of the ray-producing mode of disintegration, it can be shown for this case that the rays will now follow the exponential changes with their own true period, $\lambda_{x}$, rather than with the $\lambda_{A}+\lambda_{x}$ period. This holds true whether the rearranged uranium $X$ is present or absent initially. The calculation which gives this simple result is lengthy and may be omitted. If $\gamma$ rays accompanied the $\beta$-rays in the direct mode of change of the uranium $X$, and not in the change of rearranged uranium $X$, the $\gamma$-rays would decay with the $\lambda_{\mathrm{A}}+\lambda_{\mathrm{x}}$ period, the $\beta$-rays according to the $\lambda_{x}$ period. The difference in period would be small and might well be overlooked. 
At present there is no experimental evidence either for or against the view that the disintegration of uranium $X$ is multiple, although such evidence has been sought for in this liahoratory for some time past. It must be understood that this particular case has been taken for purposes of illustration only.

Physical Chemistry Laboratory,

University of Glasgow, Sept. 13th, 1909.

LXXVII. On the Active Deposit from Actinium in Uniform Electric Fields. By W.T. Kennedy, B.A.*

[Plate XXII.]

\section{Introduction.}

T $N$ a number of experiments which have been carried on with the emanations and the emanation products from the radioactive substances, it has been shown by Rutherford $\dagger$ that with thorium emanation the amount of activity imparted to a rod charged negatively was independent of the pressure until a pressure of $10 \mathrm{~mm}$. was reached, and that below this pressure it decreased as the pressure in the containing vessel was lowered. At $1 / 10 \mathrm{~mm}$. pressure it was only a small fraction of its maximum amount. Makower $\ddagger$ has also obtained similar effects with the excited activity from radium emanation. Further, Rutherford $\S$ experimenting with radium emanation, found that at atmospheric pressure the greater part of the active deposit went to the cathode, while only about 5 per cent. went to the anode. From these results he has drawn the conclusion that while most of the active deposit particles of radium are positively charged, some at least must carry a negative charge, inasmuch as they are drawn to the anode in electric fields.

More recently Russ \|| showed that when positively and negatively charged electrodes were placed in a vessel containing either air, sulphur dioxide, or hydrogen charged with the emanation from radium, the relative amounts of the active deposits obtained on the two electrodes varied with the pressure at which the exposures were made. With all three gases the

* Communicated by Professor J. C. McLennan, and read before the Royal Society of Canada on May $26,1009$.

+ Rutherford, Phil. Mag. Feb. 1900.

+ Nakower, Phil. Mag. Nov. 1905.

\$ Rutherford, Phil. Mag. Jan. 1903.

\|) Russ, Phil. Mag. May 1908. 